\title{
Analysis of Sports Halls in Terms of Eliminating Noise: Case Study on an Example in Podgorica, Montenegro
}

\author{
Svetislav G. Popovic ${ }^{1}$, Sanja Paunovic Zaric ${ }^{1}$ and Irena Rajkovic ${ }^{1}$ \\ 'University of Montenegro, Faculty of Architecture, Podgorica, Montenegro
}

\begin{abstract}
Noise in a learning environment is unwanted and depends on many factors, which are particularly evident in sports halls because of the noisy nature of sports activities. This paper analyses three school sports halls in Podgorica, Montenegro, in terms of detecting noise and providing guidelines for its elimination. Through three characteristic sports hall typologies, sources and numerical indicators of noise levels, generated during the usage of the sports hall for games and sports, have been detected. The results obtained through measurements give specific values that can be compared with applicable standards, and by using a comparative method, the ranking of noise levels for the three types of sports halls will be made. Through three typical examples, this paper gives specific guidelines for improving the conditions for using sports halls, with the help of positive examples in solving the same or similar problems in the region, and beyond.
\end{abstract}

Keywords: sports hall, noise, sound barriers, noise source, typology of school sports halls

\section{Introduction}

In the process of improving the educational system, strategies that are being implemented are mainly aimed at improving the curriculum, while the conditions for teaching, learning, and the impact on the environment are insufficiently treated. Through the study of sports halls and possibilities for creating a network of sports facilities in cities, it is evident that sports halls are mainly present in educational institutions: schools. (Popovic, 2014). For this reason, they represent a vital resource for research on the conditions in which physical education classes are carried out. The transmission of sound through space is one of the critical factors for quality classes. Every sound carries specific information that can be but is not necessarily understandable and useful. If the information contains too much useless and incomprehensible content, it creates noise and thus distracts students. Noise is an unwanted type of sound in the space in which classes are carried out because it has a negative impact on understanding among participants of the teaching and educational process.

The ability of teachers and students to hear one another is an essential part of academic excellence (Klatte, Bergstroem, \& Lachmann, 2013; Woolner \& Hall, 2010). Poor acoustic conditions cause discomfort and negative psychosocial behaviour among students (Crandell, Smaldino, \& Flexer, 2005), while the attention of students and their participation in class is improved in the conditions of reduced noise levels (Dockrell \& Shield, 2012). Although acoustic conditions are recognized as very important in the teaching process, they are deficient in most spaces where classes are carried out.

Speech is a combination of direct and reflected sound that travels from teacher to student. Direct sound starts from the teacher and becomes a reflected sound when it strikes one or several obstacles and surfaces in space. The position of a student in a sports hall causes the perception of a specific com-

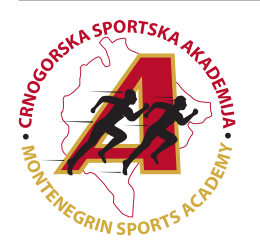

Correspondence: 
bination of direct and reflected sound. The distance between the teacher and student determines the necessary amount of acoustic energy of direct and reflected sound. Due to the size of a sports hall, this distance is larger than in a classroom. Sports halls are a noisy environment because the space is built of hard materials from which sound bounces, while the surfaces of the walls, floor and ceiling are generally smooth and hard so that they may be used for a longer time for a variety of sports and activities, which all increases the reverberation time, impairs comprehensibility of speech and increases noise level in space (Jurak, Strel, Kovač, \& Leskošek, 2015).

\section{Noise in sports halls}

The acoustic conditions in which classes are carried out are particularly demanding in sports halls in which physical education is carried out in schools. A large number of students stay still and run in halls, and sometimes different groups of students at the same time perform different activities. Because of the activities that are carried out in sports halls: using balls for different sports, running, loud cheerleading, using whistles, etc., sports halls in schools are most subject to the negative impact of noise during classes.

The poor acoustics in these spaces is also a health problem for teachers. As students, due to noise, can barely hear their teachers and therefore their attention is reduced during classes in a larger space, teachers barely manage to be loud enough to overcome the surrounding noise and convey the desired message to students. Therefore, voice (Kovač, Leskošek, Hadžić, \& Jurak, 2013; Simberg, Sala, Vehmas, \& Laine, 2005; Smith, Kirchner, Taylor, Hoffman, \& Lemke, 1998) and hearing problems (Kovač et al., 2013; Lemoyne, Laurencelle, Lirette, \& Trudeau, 2007) are among the most common occupational health problems faced by physical education teachers. Due to the above-described working conditions, physical education teachers have voice problems more often than other teachers do (Jonsdottir, Boyle, Martin, \& Sigurdardottir, 2002; J. Preciado, Perez, Calzada, \& P. Preciado, 2005; Smith et al., 1998). Frequent exposure to noise has long-term consequences, such as fatigue during the day, increased psychological and emotional tension, feelings of nervousness and irritation, concentration problems, roughness of voice, and coughing (Augustynska, Kaczmarska, Mikulski, \& Radosz, 2010). For the above reasons, it is necessary to analyse the noise level in sports halls, detect the problem, and address resolving the noise and its impact on classes, teachers and students.

\section{Standards and Framework}

In this paper, the applicable national and international standards have been taken into consideration. Noise regulation includes measuring techniques, specifications for the equipment used, and procedures for making accurate and reproducible measurements, established by the national, state or provincial, and municipal levels of government.

"Acoustics - Guide to International Standards on the measurement of airborne acoustical noise and evaluation of its effects on human beings" is the title of ISO 2204, that defines basic terms and measuring methods and also gives a reference list of other applicable standards (Herlufsen, 1984). Wróblewska (2010) has studied acoustical standards used in the design of school spaces in Europe, America, and New Zealand. Two documents, SFS 5907:2004 and NS 8175:2005, make a difference between the acoustical classes of building depending on the values that are recommended. "The main purpose of regulations is to decrease the noise and to ensure the proper acoustical conditions for good communication, speech intelligibility and the sound of music [...] Rooms for education of students with hearing impairment or language classrooms should have the acoustical requirements concerning reverberation stricter by about 20\%".

In accordance with national standards, the noise indicator is a physical measure that expresses the level of noise in the environment in relation to its adverse impact, while the limit value of noise is the highest allowed noise value in the environmental expressed by the indicator Lden or Lnight and Lday and Levening, respectively (Law on the Protection against Environmental Noise - Official Gazette of Montenegro, No 28/11, 01/14). The rulebook on the limit values of noise in the environment, the method of determining a noise indicator and acoustic zone and methods of evaluation of adverse effects of noise, defines the limit values of noise in the acoustic zones. These values refer to the total noise level from all sources in the acoustic zones. According to this rulebook, noise must not exceed the limit value of the noise level of $65 \mathrm{~dB}$ (A). The method for determining the equivalent noise level is determined by MEST standards ISO 1996-1 and ISO 1996-2 MEST (Official Gazette of Montenegro, No 28/11, 01/14).

Montenegro indicated that the Noise Directive 2002/49/ EC had been transposed mainly by the Law on Environmental Noise Protection (2011) and the Rulebook on limit values of environmental noise and acoustical zoning (2011). The legal framework for the stipulation of technical requirements and conformity assessment procedures for products covered by Directive 2000/14/EC (manufacturing, importing, and placing on the market and/or putting in use are): the Law on Protection against Environmental Noise (Official Gazette of Montenegro, No 28/11, 01/14); Rulebook on conformity marking for sources of noise (Official Gazette of Montenegro, No 13/14) and the Rulebook is fully aligned with the requirements of Directive 2000/14/EC. Neither of these regulations recognizes noise protection as an essential element in designing school facilities, and school sports halls are not recognized as a separate category and a potential cause of noise pollution.

\section{Methods}

Noise is created in sports halls directly through each maker of unwanted or harmful sound, i.e., by each usage of halls in which attention was not paid either to the presence or the solution of noise pollution. The study carried out measurements in the examples of three topologically different sports halls of elementary schools in Podgorica (Montenegro): Sports Hall 1 - a free standing school sports hall, Sports Hall 2 - a sports hall located in the centre of a primary school, and Sports Hall 3 - a curved soccer tent with a steel construction positioned in a school yard. The economic and social statuses dictate the guidelines and the direction of improving working conditions in halls in terms of noise generated by their usage.

Noise measurements were made with detailed documentation of the measurements and results. The measurement report contains the following information:

- A precise sketch of the school halls' measurements with the exact dimensions (room size, room volume, dimensions of openings, cross sections etc.), as well as the location of the microphone in the objects being measured.

- Standards and framework, according to which measure- 
ments were made. According to national standards, the measurement must take at least 15 minutes. Otherwise, the measurement is not relevant.

- The type and serial number of the measuring instruments used are a Bruel \& Kjaer phonometer, type 2250B (specially made for noise measuring) and a Bruel \& Kjaer Microphone, type 4189 (for noise measuring).

- Calibration was carried out using the reference calibre for sound, which is calibrated by the absolute reciprocal method in a laboratory for non-electrical measures ML-03 (Technical Test Center, Sector for Meteorology in Belgrade). Calibration was done just before measurement by a Bruel \& Kjaer acoustic calibrator, type BK4231. Measurement uncertainty is expressed in accordance with EA-4/02; uncertainty corresponds to a coverage probability of approximately $95 \%$. (Calibration date: November 6, 2016).

- The type of sound that has been measured is NOISE.

- The background noise level was measured for Sports Halls 1 and 2. Background noise was not detected.

- The location of the measurement was Podgorica, Montenegro. The measurements have been carried out along one receiver line at the height of 1.3-1.5 $\mathrm{m}$ above the floor, at least $2 \mathrm{~m}$ away from walls and partitions.

- Atmospheric conditions at the time of measurement were as follows: the temperature $(\mathrm{t})$ was from $17^{\circ} \mathrm{C}$ to $20^{\circ} \mathrm{C}$, relative humidity $(\mathrm{Rv})$ had a range from $27 \%$ to $24 \%$, wind speed and direction $(\mathrm{V}) \mathrm{N} / \mathrm{a}$, air pressure $(\mathrm{P})$ was $1017.0 \mathrm{mb}$ (Freemeteo, 2017).

- The date of measurement performance is March 17, 2017, in the interval between 10:05 a.m.-2:35 p.m. The exact time of measurement is given in each graph.

\section{Results}

\section{Sports Hall 1}

Sports Hall 1 is a free standing school Sports Hall in the Maksim Gorki primary school and has a volume of approximately $2140.6 \mathrm{~m}^{3}$, with a floor area of approximately $389.2 \mathrm{~m}^{2}$ and a height of $5.5 \mathrm{~m}$. From a height of $4.1 \mathrm{~m}$ above the ground floor, the walls have been lined with PVC openings with an area of approximately $71.15 \mathrm{~m}^{2}$. The windows do not have any acoustical window inserts. The dimensions of the hall are 27.8 $\times 14 \times 5.5 \mathrm{~m}$. The hall is designed as a sports hall, without any bleachers and with sufficient ceiling height for the performance of most sports activities. The floor plan, cross section, and hall appearance are presented in Figure 1.
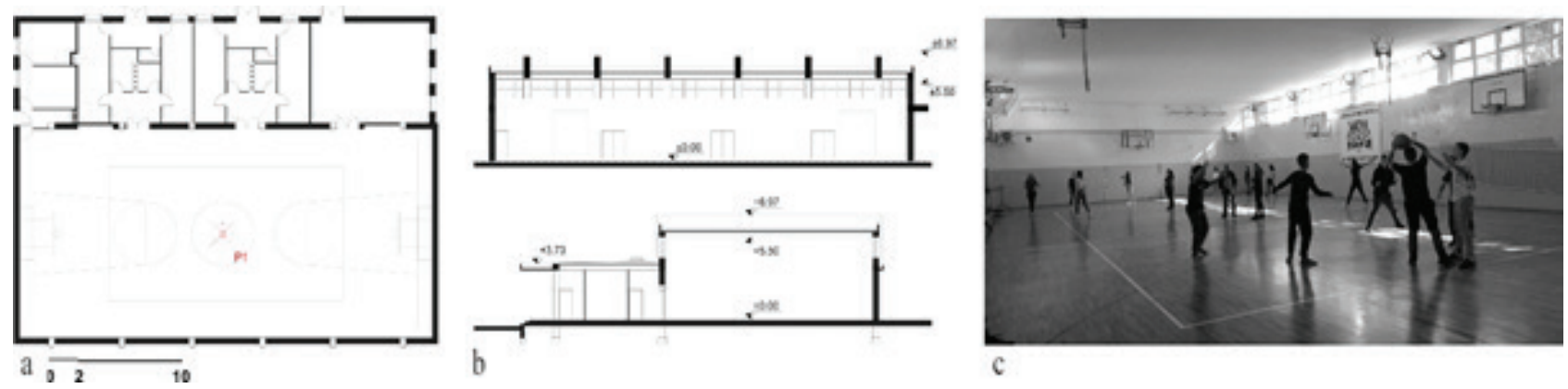

Figure 1. Sports hall in Maksim Gorki primary school in Podgorica, Montenegro ( $a$ - Hall plan with the position of the measuring instrument; $b$ - Hall cross section; c - Free standing school)

Figure 1a also shows the position of the measurement instrument used. Measurements were carried out along one receiver line at the height of $1.5 \mathrm{~m}$ above the floor at the central axes of the room. During measurements the outdoor micro-climate conditions were as follows: the temperature $(\mathrm{t})$ was $17^{\circ} \mathrm{C}$, relative humidity (Rv) had a range from 27 to $24 \%$, wind speed and direction $(\mathrm{V}) \mathrm{N} / \mathrm{a}$ and the air pressure $(\mathrm{P})$ was $1017.0 \mathrm{mb}$. The exact time of measurement is given in the graphs in Figure 2.
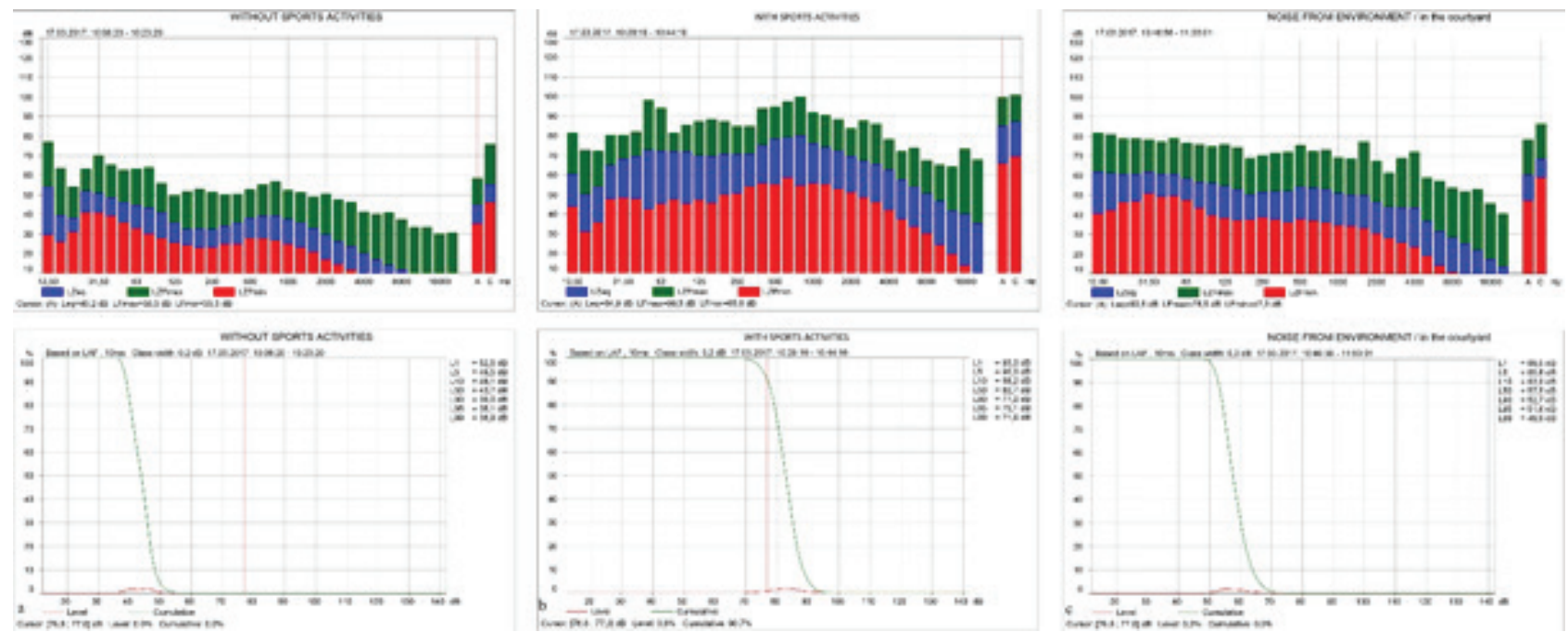

Figure 2. a - Noise level in sports hall without activities; b - Noise level in sports hall during activities; c - Environmental noise level in the yard near the sports hall 
The sports hall was renovated in 2014. During the renovation, the wall coverings made of carpet (for sound isolation) were removed, which caused more complex and inadequate acoustic conditions. Figure 2 shows three characteristic situations: the sports hall without activities (Figure 2a), the sports hall during activities (Figure 2b) and the environmental noise level in the yard near the sports hall (Figure 2a). Figure 2 shows that the noise equivalent is $45.2 \mathrm{~dB}$ (Figure 2a) before class and ranges up to $84.9 \mathrm{~dB}$ (Figure b) during class with 28 students. The students were exposed to the noise equivalent from $65.8 \mathrm{~dB}$ (Figure $2 \mathrm{~b}$ ) to $99.5 \mathrm{~dB}$ (Figure 2b) during class. Infiltration of external noise was not detected, which had been proven by environmental noise measurements (Figure 2c). Taking into account the fact that teachers sometimes have up to 7 classes per day, during class $90.7 \%$ of measurements of the noise level were above $77 \mathrm{~dB}$ (Figure $2 \mathrm{~b}$ ), which falls within the global determinations of hearing risk that is based on exposure for a maximum limit of eight hours per day.

\section{Sports hall 2}

Sports Hall 2 is an integrated part of the Milorad-Musa Burzan primary school building and has a volume of approximately $1281.69 \mathrm{~m}^{3}$, with a floor area of approximately 212.2 $\mathrm{m}^{2}$, which is the sports area and a height of $6.04 \mathrm{~m}$, and approximately $120 \mathrm{~m}^{2}$ of toilets and wardrobe with a height of $4.12 \mathrm{~m}$. In the hall, there are 10 windows with PVC openings that cover an area of approximately $25.5 \mathrm{~m}^{2}$. Windows do not have any acoustical window inserts. The floor plan, cross section, and hall appearance are presented in Figure 3.
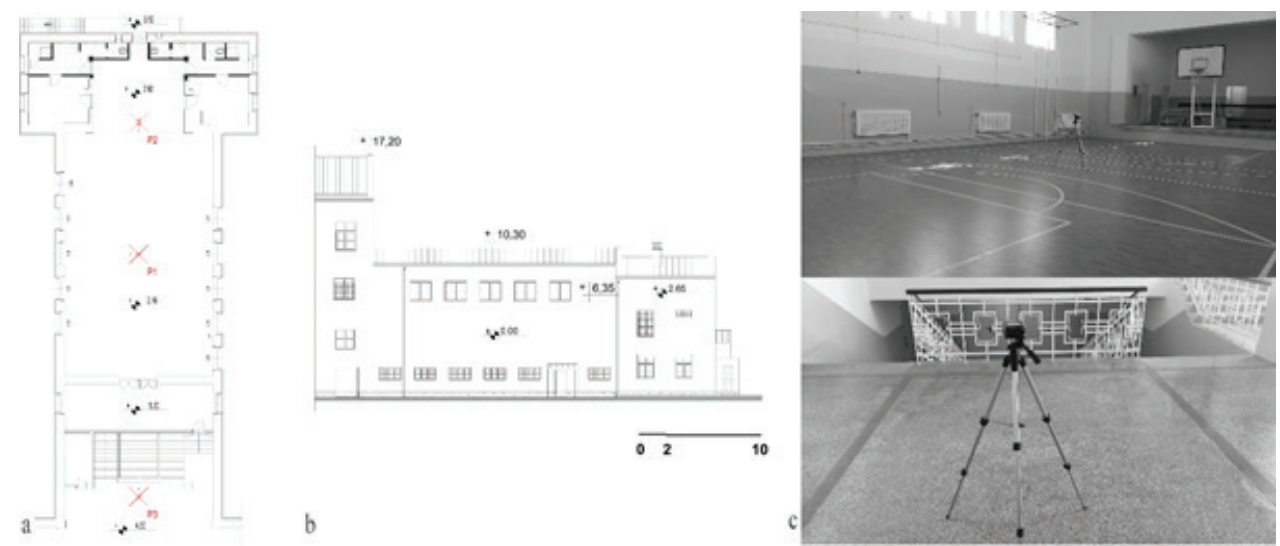

Figure 3. Sports hall in Milorad Musa Burzan primary school in Podgorica, Montenegro (a - hall plan with the position of the measuring instrument; b - Longitudinal façade; c - Free standing school sports)

Figure $3 \mathrm{a}$ also shows the position of the measurement instrument used. Measurements were carried out along one receiver line at the height of $1.5 \mathrm{~m}$ above the floor at the central axes of the room. During measurements the outdoor micro-climate conditions were as follows: the temperature $(t)$ was $19^{\circ} \mathrm{C}$, relative humidity (Rv) $24 \%$, wind speed $19-20 \mathrm{~km} / \mathrm{h}$ and direction $(\mathrm{V})$ was N/a, and the air pressure $(\mathrm{P})$ was 1016.0 $\mathrm{mb}$. The exact time of measurement is given in the graphs in Figure 4 . The sports hall was renovated in 2016 in the context of improving the thermal conditions.

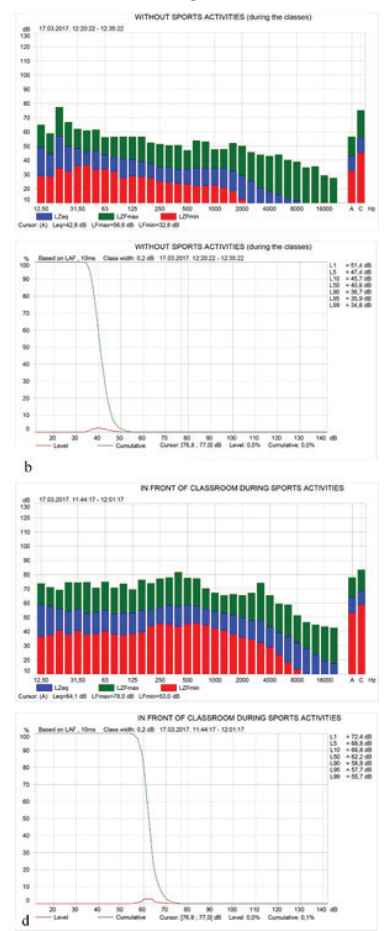

Figure 4. a - Noise level in the sports hall without activities (during the class break); b - Noise level in the sports hall without activities (during classes); $c$ - Noise level in the sports hall during activities; $d$ - Noise level in front of the classrooms during sports activities in the hall 
Figure 4 shows four different situations: the hall without activities - during the class break (Figure 4a), the hall without activities - during class (Figure $4 \mathrm{~b}$ ), the hall during sports activities (Figure 4c) and noise from the hall measured in front of the classrooms (Figure 4d). Figure 4 shows that the noise equivalent without sport activities during the class break is $51.8 \mathrm{~dB}$ (Figure $4 \mathrm{a}$ ) and during classes $42.8 \mathrm{~dB}$ (Figure $4 \mathrm{~b})$. The noise equivalent in the hall during sports activities during class with 32 persons in the hall and which was 87.5 $\mathrm{dB}$ (Figure 4c). Students were exposed to noise levels up to $102.3 \mathrm{~dB}$ (Figure 4c) during class. Also, Figure 4 presents the impact of noise from the hall on the school environment (the hall in front of the classrooms), where the noise equivalent was measured starting from $64.1 \mathrm{~dB}$, with a maximum level of $78.0 \mathrm{~dB}$ (Figure 4d). It shows the impact of hall noise during sports activities on classes in classrooms, which was especially increased after renovation when old wooden doors were replaced with new metal ones.

\section{Sports hall 3}

Sports Hall 3 is a free standing soccer curved tent with a steel construction positioned in the school yard at Sutjeska primary school and has a volume of approximately 8445.2 $\mathrm{m}^{3}$, with a floor area of approximately $1053.5 \mathrm{~m}^{2}$ and a height of $10.5 \mathrm{~m}$. The sports hall does not have any openings, but the tent is semi-transparent and thus lets enough daylight in. No HVAC systems are installed in the structure. The dimensions of the curved tent are $24 \times 43 \times 10.5 \mathrm{~m}$. The floor plan, cross section, and hall appearance are presented in Figure 5.
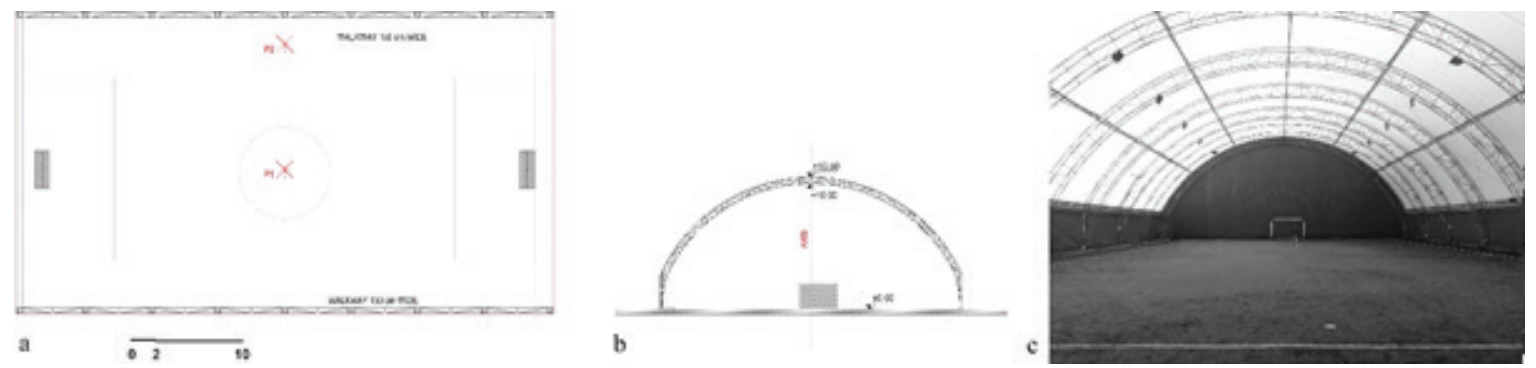

Figure 5. Sports hall in Sutjeska primary school in Podgorica, Montenegro ( $a$ - hall plan with the position of measuring instruments; $b$ - hall cross section; c - free standing soccer curved tent with a steel construction positioned in the school yard)

It also shows the position of the measurement instruments used. Measurements were carried out along one receiver line at the height of $1.5 \mathrm{~m}$ above the floor at the central axes of the room in the case when there were no activities and $4 \mathrm{~m}$ from the walls and partitions, also in the central axes during sports activities. During measurements the outdoor micro-climate conditions were as follows: temperature (t) range from $19^{\circ} \mathrm{C}$ to $20^{\circ} \mathrm{C}$, relative humidity (Rv) ranged from $24 \%$ to $23 \%$, wind speed was $11-17$ $\mathrm{km} / \mathrm{h}$ and direction $(\mathrm{V})$ was $\mathrm{N} / \mathrm{a}$, air pressure $(\mathrm{P})$ was $1015.0 \mathrm{mb}$. The exact time of measurement is given in the graphs in Figure 6. During measurements, the interior temperature was $5^{\circ} \mathrm{C}-6^{\circ} \mathrm{C}$ higher than the outdoor temperature, which was caused by the semi-transparent tent material and the lack of openings and a ventilation system.

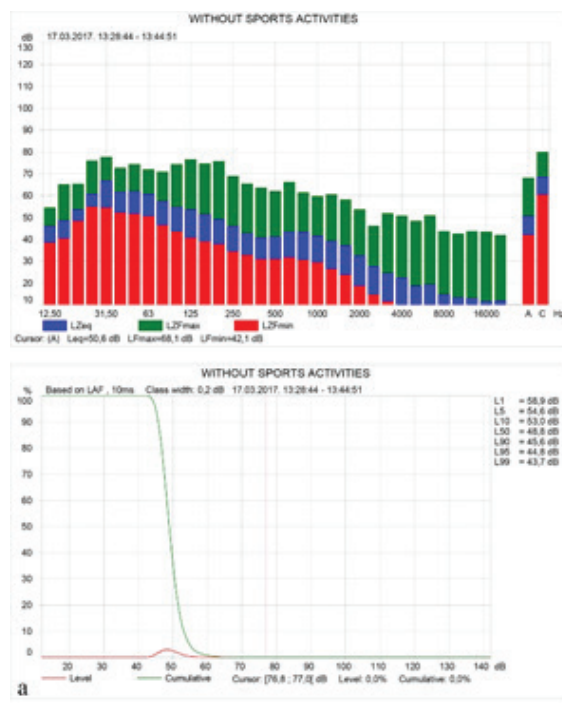

Figure 6 shows two typical situations: the hall without activities (Figure 6a) and the hall during activities (Figure 6b). Figure 6 shows that the noise equivalent was $50.6 \mathrm{~dB}$ (Figure 6a) before class up to $69.5 \mathrm{~dB}$ (Figure $6 \mathrm{~b}$ ) during class with 16 students. Students were exposed to a noise equivalent of $65.8 \mathrm{~dB}$ (Figure $6 \mathrm{~b}$ ) up to $99.5 \mathrm{~dB}$ (Figure $6 \mathrm{~b}$ ) during class. The measured noise level was above $77 \mathrm{~dB}(\mathrm{~B})$ during $3.3 \%$ of the measuring time. Although the noise impact on the tent from the environment was higher than in cases 1 and 2, the four times higher dimension of the hall, the curved tent shape and the tent absorbing characteristics (like curtains), as well as the artificial grass on the hall floor, completely reduced the noise impact in this type of sports hall. In contrast to the poor thermal conditions, the acoustic conditions were far better than in traditional sports halls.

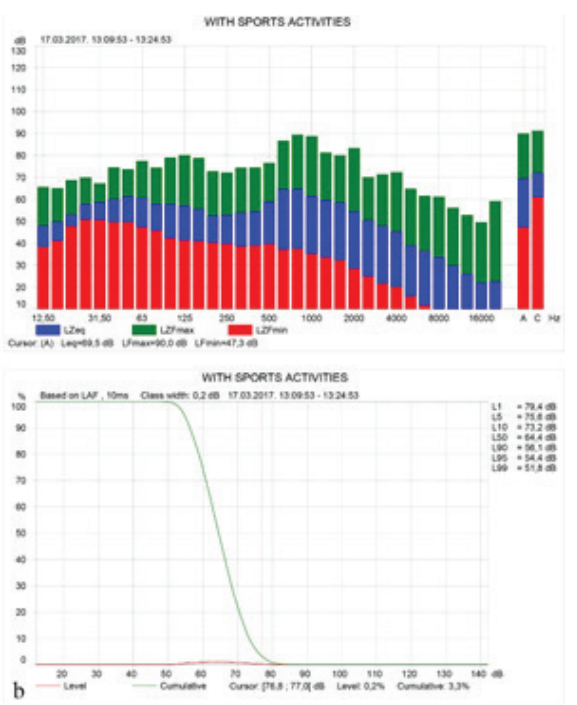

Figure 6. a - Noise level in the tent hall without activities; $b$ - Noise level in the tent hall during activities 


\section{Discussion}

The noise equivalent level for large sports halls during sports activities during the period of research was between 69.5-87.5 dB. The lowest level was measured in the tent sports hall (Sutjeska primary school) due to the large space, area and cubature and because of the artificial grass floor covering and pvc roof covering which are good absorbers of noise. The highest level of noise was measured in Sports Hall 2 (MiloradMusa Burzan primary school), where the hall is integrated into the school building, and because it was in a stone building. This sound value is high, and it has an adverse impact on the nervous systems of both students and teachers. Additionally, in Milorad Musa Burzan primary school, it was detected that the noise from the sports hall could have an impact on classes, because the noise equivalent was $64.1 \mathrm{~dB}$. This value is within the acceptable healthy limits (noise period), but it is not acceptable in terms of the classrooms (calmness standard), which is 35 (A) dB. In the Maksim Gorki primary school, the noise equivalent of $84.9 \mathrm{~dB}$ is high for educational activities, and being exposed to it for a more extended period could create health problems, especially for teachers.

\section{Recommendations for resolving noise}

The measuring results have shown that the existing halls do not have any adequate acoustical features. A series of architectural solutions can be applied to the halls in terms of hall design retrofitting, in order to provide better acoustical design, as well as noise protection, based on sound diffusors, noise barriers, and sound reflectors. School hall noise problems can be solved by a system of sound-absorbing units or new surface materials. Solutions range from retrofitting of primary building elements: the construction, the floor, the wall (openings) and the ceiling, the way of applying an insulating material, or in the form of plaster and the absorber installed inside the sports hall volume. Materials and construction elements that shape the finished spaces determine how sound will be perceived in that space (Cavanaugh, Tocci, \& Wilkes, 2010).

Sound absorption coefficients of the floor, wall and ceiling materials and openings of the hall should be at the 125-4000 $\mathrm{Hz}$ frequency range in 1/1 octave band (Mezzo Stüdyo Co. Ltd., 2014). Ceilings and walls are more convenient for the installation of sound absorbers. The problem may arise if the hall

\section{Acknowledgements}

There are no acknowledgements.

\section{Conflict of Interest}

The authors declare that there are no conflicts of interest.

Received: 09 July 2019 | Accepted: 19 September 2019 | Published: 01 February 2020

\section{References}

Augustynska, D., Kaczmarska, A., Mikulski, W., \& Radosz, J. (2010). Assessment of Teachers' Exposure to Noise in Selected Primary Schools. Archives of Acoustics, 35(4), 521-542.

Barron, M. (2010). Auditorium Acoustics and Architectural Design, $2^{\text {nd }}$ edition. London: Spon Press.

Crandell, C., Smaldino, J.J., \& Flexer, C. (2005). Sound-field applications: Applications to speech perception and classroom acoustics, 2nd ed. New York: Thomson.

Cavanaugh, W.J., Tocci, G.C., \& Wilkes, J.A. (2010). Architectural Acoustics. New Jersey, US: John Wiley \& Sons, Inc.

Dockrell, J.E., \& Shield, B. (2012). The impact of sound-field systems on learning and attention in elementary school classrooms. J Speech Lang Hear Res, 55(4), 1163-1176. dimensions are tight, or if the ceiling is too low. In that case, reducing the hall volume should be avoided.

The possibilities among physical variable acoustic elements to be considered as physical-adjustable elements for the ceiling, wall, floor and openings, such as:

- Acoustic baffles and banners from a suspended ceiling system or mounted on the wall. Banners are usually free hanging and can be retracted through slots or folded into well-sealed boxes (Barron, 2010);

- Movable reflecting panels with different acoustical characteristics of different surfaces;

- Variable scattering elements could be mounted on horizontal ceiling surfaces that could be transformed into a coffered surface with slats lowered through slots from above. "Free-standing scattering elements could also be lowered to introduce scattering. A change in degree of scattering of a surface carries less impact than change in absorption or orientation" (Barron, 2010);

- Sound absorption modules and materials that can be applied on the wall or ceiling. Possible options range from acoustic fiberglass, acoustic foam, acoustic partitions, acoustic cotton, hanging baffles, Echo elimination, cellulose panels, multi-layer sound absorption panels, wool panels covered with acoustically transparent fabric, etc.;

- Sound diffusors that reduce the intensity of sound by scattering it over an expanded area (Quadra pyramid diffusors, pyramidal diffusors, double duty diffusors, quadratic diffusors etc.);

- Fabric covering or fabric wrapped panels as sound-absorbing curtain modules in front of tribune's rear wall, side walls, front walls and at the openings between the service and sports areas (Ulusoy, 2014);

- Replacement of existing windows with acoustical window inserts;

- Replacement of floor surfaces with different sound absorption characteristics etc.

The budget needed for satisfactory remediation has been estimated to vary in the range from $4.5 \%$ to $6.9 \%$ of the overall construction cost. The results also pointed out the critical concerns of acoustical design, particularly for sports halls (Ulusoy, 2014). Continuous development of materials and technology are meeting the needs for resolving noise pollution in school sports halls.

Freemeteo. (2017). Weather forecasts for all cities, villages and toponyms. Retrieved 03/17, 2017, from freemeteo.rs/vreme/podgorica/istorija/prot eklidan $/$ ?gid $=3193044 \&$ station $=4432 \&$ date $=2017-03-23 \&$ language $=$ serbi an\&country=Montenegro

Herlufsen, H., (1984). Dual Channel FFT Analysis (Part I and Part II), Brüel \& Kjær Technical Review No. 1 \& 2.

Popovic, S. G. (2014). Urban parameters for planning the network of physical education facilities in Montenegro. Sport Mont, XII(40-41-42), 131-139.

Preciado, J., Perez, C., Calzada, M., \& Preciado, P. (2005). Prevalence and incidence studies of voice disorders among teaching staff of La Rioja, Spain. Clinical study: questionnaire, function vocal examination, acoustic analysis and videolaryngostroboscopy. Acta Otorrinolaringol Esp, 56(5), 202-210. http://dx.doi.org/10.1016/S0001-6519(05)78601-5

Jonsdottir, V.I., Boyle, B.E., Martin, P.J., \& Sigurdardottir, G. (2002). A comparison of the occurrence and nature of vocal symptoms in two groups of Icelandic teachers. Logoped Phoniatr Vocol, 27(3), 98-105.

Jurak, G. Strel, J., Kovač, M., \& Leskošek, B. (2015). Acoustics in School Sport Halls and Its Implications for Physical Education. Croatian Journal of Education, 17(3), 65-95.

Klatte, M., Bergstroem, K., \& Lachmann, T. (2013). Does noise affect learning? A short review on noise effects on cognitive performance in children. Frontiers in psychology, 4, 578. http://dx.doi.org/10.3389/fpsyg.2013.00578 Kovač, M., Leskošek, B., Hadžić, V., \& Jurak, G. (2013). Occupational health 
problems among physical education teachers: a cross-sectional study. Kinesiology, 45(1), 92-100.

Lemoyne, J., Laurencelle, L., Lirette, M., \& Trudeau, F. (2007). Occupational health problems and injuries among Quebec's physical educators. Appl Ergon, 38(5), 625-634. http://dx.doi.org/10.1016/j.apergo.2006.06.004

Simberg, S., Sala, E., Vehmas, K., \& Laine, A. (2005). Changes in the prevalence of vocal symptoms among teachers during a twelve-year period. J Voice, 19(1), 95-102. http:// dx.doi.org/10.1016/j.jvoice.2004.02.009

Smith, E., Kirchner, H.L., Taylor, M., Hoffman, H., \& Lemke, J.H. (1998) Voice problems among teachers: differences by gender and teaching characteristics. J Voice, 12(3), 328- 334

Ulusoy, G. (2014). Acoustical improvement of typical sport halls for multipurpose use. A thesis submitted to the graduate School of natural and applied sciences of Middle East Technical University.

Woolner, P., \& Hall, E. (2010). Noise in schools: a holistic approach to the issue. Int J Environ Res Public Health, 7(8), 3255-3269. http://dx.doi.org/10.3390/ ijerph7083255

Wróblewska, D. (2010). Acoustical Standards Used in Design of School Spaces. Institute of Physics, Polish Academy of Science: Acta Physica Polonica A, 118(1), 186-189. 